\title{
Dystrophic muscle environment induces changes in cell plasticity
}

\author{
Herve Faralli $^{1}$ and F. Jeffrey Dilworth ${ }^{1,2,3}$ \\ ${ }^{1}$ Sprott Center for Stem Cell Research, Regenerative Medicine Program, Ottawa Hospital Research Institute, Ottawa, Ontario \\ K1H 8L6, Canada; ${ }^{2}$ Department of Cellular and Molecular Medicine, University of Ottawa, Ottawa, Ontario K1H 8M5, Canada
}

Fibro-adipogenic progenitors (FAPs) reside in the muscle, where they facilitate myofiber regeneration. Under normal conditions, FAPs lack myogenic potential and thus do not directly contribute to regenerated myofibers. Surprisingly, Saccone and colleagues (pp. 841-857) demonstrated that the dystrophic muscle environment causes FAPs to adopt a chromatin state that imparts these cells with myogenic potential. In this context, treatment of muscle with deacetylase inhibitors activates a BAF60cmyomiR transcriptional network in FAPs, blocking adipogenesis and driving muscle differentiation.

Skeletal muscle displays the remarkable ability to regenerate itself from both acute and chronic damage. This regenerative capacity decreases with age, which results in a progressive degenerative muscle wasting that is termed sarcopenia. While muscle satellite cells have been established as the main cell type contributing to muscle fiber regeneration, several other muscle-resident cell populations play a supporting role to ensure efficient muscle repair (Judson et al. 2013). Among these are mesenchymal progenitor cells, termed fibro-adipogenic progenitors (FAPs), which can differentiate into either fibroblasts or adipocytes (Joe et al. 2010). While FAPs themselves do not contribute directly to the regenerated muscle fibers, they release promyogenic signals/factors that in turn stimulate the regenerative capacity of satellite cells (Joe et al. 2010). Upon damage to a healthy muscle, proinflammatory immune cells are mobilized to clear the debris. Within the immune cell populations, eosinophils release IL-4 and IL-13, which results in activation of the FAP population (Heredia et al. 2013). Activated FAPs can then differentiate toward the fibroblast lineage to create a fibrotic scaffold that supports muscle reconstruction (Joe et al. 2010). Furthermore, FAPs release promyogenic cytokines that stimulate the satellite cell to regenerate the muscle fiber (Joe et al. 2010).

[Keywords: SWI/SNF chromatin remodeling; BAF60; microRNA; HDAC; FAPs; muscular dystrophy]

${ }^{3}$ Corresponding author

E-mail jdilworth@ohri.ca

Article is online at http://www.genesdev.org/cgi/doi/10.1101/gad.241182.114.
In the context of chronic muscle degeneration, as is observed in muscular dystrophy, the regenerating muscle begins to accumulate fibrotic and fatty tissue. Evidence suggests that FAPs are a contributing cell population to this dystrophic muscle pathology, leading to decreased contractility and altered metabolism within the muscle (Uezumi et al. 2010). Thus, several groups have examined the therapeutic targeting of FAPs using small molecules to inhibit fibrogenic and adipogenic differentiation and ultimately delay dystrophy progression. The HDAC inhibitor TSA was shown to block adipogenic differentiation of FAPs and improve regeneration of young (but not old) mdx mice (Mozzetta et al. 2013), a widely used model for Duchenne muscular dystrophy (DMD). This work demonstrated the potential of targeting FAP function with HDAC inhibitors to treat DMD, although a mechanism of action was not established. Furthermore, the reasoning for the beneficial effects of HDAC inhibitors exclusively in young mdx mice was unknown.

In this issue of Genes \& Development, Saccone et al. (2014) provide evidence that the improved regeneration of young mdx muscle after HDAC inhibitor (TSA) treatment is a result of profound changes in the epigenetic landscape of FAPs that promote the myogenic lineage at the expense of their adipogenic potential. Using both formaldehyde-assisted isolation of regulatory element (FAIRE) and nuclease accessibility assays, the investigators demonstrated that TSA treatment leads to a global change in chromatin organization in FAPs isolated from young mdx mice that was not observed in FAPs isolated from either young wild-type or older $\mathrm{mdx}$ mice. Coincident with this global change in chromatin structure, RNA sequencing identified a significant up-regulation of muscle gene expression with a concomitant decrease in adipose genes in FAPs from young $\mathrm{mdx}$ mice treated with TSA. Furthermore, it was shown that FAPs harvested from TSA-treated young $\mathrm{mdx}$ mice behave differently from their wild-type counterparts harvested from unperturbed muscles in that they could form myosin heavy

(C) 2014 Faralli and Dilworth This article is distributed exclusively by Cold Spring Harbor Laboratory Press for the first six months after the fullissue publication date (see http://genesdev.cshlp.org/site/misc/terms.xhtml). After six months, it is available under a Creative Commons License (Attribution-NonCommercial 4.0 International), as described at http:// creativecommons.org/licenses/by-nc/4.0/. 
chain-positive myotubes, a hallmark of myogenic differentiation. This acquisition of myogenic potential was surprising, since FAPs have previously been extensively characterized for their ability to differentiate into various cell types and shown not to possess myogenic potential when isolated from muscles of wild-type mice that were not exposed to HDAC inhibitors (Joe et al. 2010). These results suggest that the diseased muscle creates a local environment that alters the chromatin state in these progenitor cells such that they become susceptible to HDAC inhibitor-mediated induction of the myogenic lineage. Further exploring the mechanism by which HDAC inhibitors induce FAPs from young mdx muscle to differentiate toward the myogenic lineage, the investigators identified the MyoD and BAF60c-myomiR network as a key determinant of FAP myogenic potency (Fig. 1). In this network, treatment of FAPs with HDAC inhibitors leads to the expression of MyoD, a master regulator of myogenesis (Davis et al. 1987), and the expression of BAF60c, a key component of the SWI/SNF chromatin remodeling complex that is required for establishing a transcriptionally permissive state at muscle gene promoters (Forcales et al. 2011). Furthermore, HDAC inhibitors allow for the expression of miR-1.2, miR-133a, and miR-206 (collectively known as the myomiRs [myogenic microRNAs]), which have been shown to target the mRNAs encoding competing BAF60 subunits-BAF60a and BAF60b (Goljanek-Whysall et al. 2012) —and are part of an alternate SWI/SNF complex that might otherwise drive adipogenic differentiation. Thus, the investigators have identified a key axis of gene expression in which the epigenome established through a novel cross-talk between noncoding RNAs (myomiRs) and the chromatin remodeling machinery (BAF60 subunits of the SWI/SNF complex) plays a determining role in the plasticity of HDAC inhibitor-treated FAPs in response to muscle injury.

The most surprising finding of this study is the fact that the myogenic potential of FAPs is limited to cells derived from the muscle of young mdx mice. As FAPs are not thought to express the dystrophin gene (mutations in the dystrophin gene are at the origin of DMD), it appears that muscle degeneration in young $\mathrm{mdx}$ muscle creates an environment that modifies the epigenetic state of FAPs to establish an altered potency within these cells. The dystrophin-independent nature of this altered cell plasticity is strongly supported by the investigators' finding that myogenic potential can also be acquired in young FAPs after cardiotoxin-induced injury. This injury-induced acquisition of myogenic potential is exciting in light of recent work reporting that $\mathrm{pH}$-induced stress of $\mathrm{CD} 45^{+}$ cells from the spleen induces a reprogramming of the epigenome to establish a totipotent cell state (Obokata 2014). While the $\mathrm{pH}$-induced reprogramming of $\mathrm{CD}^{+} 5^{+}$ cells still requires confirmation from independent laboratories, it is intriguing to speculate that the muscle environment induced by the chronic myofiber breakdown in muscular dystrophy or cardiotoxin-induced muscle injury leads to a stress response that reprograms the epigenetic state of FAPs in young mice to a cell type of altered potency. Supporting the possibility that the damaged muscle environment alters the plasticity of nonmyogenic cells, myogenic commitment of a mesenchymal $\left(\mathrm{CD}^{+} 4^{+} /\right.$ $\mathrm{Scal}^{+}$) cell population was recently reported in cancer cachexia (He et al. 2013). Nevertheless, the question remains as to why the muscle environment of older $\mathrm{mdx}$ mice does not confer a similar alteration of cell plasticity on its resident FAPs. A first possibility could be that the reduced level of necrosis observed in the aged $\mathrm{mdx}$ mice does not provide sufficient stress to induce the epigenetic reprogramming required for FAPs to acquire altered cell plasticity. Indeed, young mdx mice display intense skeletal muscle necrosis due to intense degeneration and regeneration of the skeletal muscle (De Luca 2012). However, stabilization of the dystrophic pathology in aged $\mathrm{mdx}$ mice leads to a gradual decrease in necrosis and may create a less stressful environment for FAPs. Alternatively, it may be
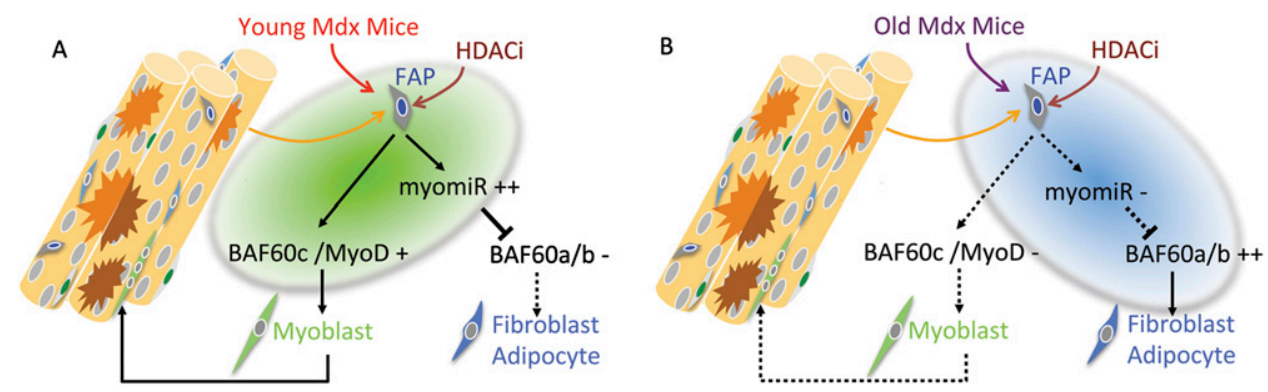

Figure 1. HDAC inhibitors induces an unexpected change in chromatin structure that permits muscle differentiation of FAPs from young $\mathrm{mdx}$ mice. $(A)$ In young $\mathrm{mdx}$ mice, treatment with the HDAC inhibitor TSA induces an up-regulation of the myomiR (miR-1, miR-206, and miR-133) microRNAs as well as MyoD and BAF60c expression in the fibroadipogenic progenitors (FAPs). As a consequence of myomiR up-regulation, the BAF60a and BAF60b subunits of the SWI/SNF complex are down-regulated via direct targeting by the microRNAs. This change in SWI/SNF complex subunit composition prevents adipogenesis while driving the FAPs toward a myogenic lineage. $(B)$ In older mdx mice, chromatin has less plasticity and does not activate the myomiR/BAF60c transcriptional network in response to HDAC inhibitor treatment. Thus, FAPs from older mdx mice continue to express the BAF60a and BAF60b subunits of the SWI/SNF complex after HDAC inhibitor treatment and are unable to adopt a myogenic gene expression program. Satellite cells are represented by dark-green nuclei, myoblasts are represented by light-green cytoplasm, FAPs are represented by dark-blue nuclei, and fibroblasts are represented by light-blue cytoplasm. The solid lines represent a strong propensity to activate a pathway, while the dotted lines indicate a weak propensity to activate a pathway. 
that FAPs from older mice establish a more stable epigenetic state, increasing their resistance to extracellular stresses that might alter their plasticity. While the epigenetic state of FAPs has yet to be examined at any point in development, studies of epigenetic modifications in satellite cells have demonstrated age-related alterations in histone methylation. For example, global levels of the transcriptionally repressive mark of histone H3K27 trimethylation (H3K27me3) are significantly increased in satellite cells of aged mice (Liu et al. 2013). One could thus imagine that a similar increase in global H3K27me3 levels in FAPs from aged mice would lead to a decrease in chromatin plasticity and lay the basis for these cells' inability to acquire myogenic potential after HDAC inhibitor treatment. Comparative genome-wide analysis of histone modifications in FAPs of young and old mice will help resolve this question. At the same time, it will be important to examine the myogenic potential of HDAC inhibitor-treated FAPs isolated from older mice after cardiotoxin-induced muscle injury to confirm that loss of muscle potency is related to the aging of FAPs and not to the age-related changes in phenotype described in mdx muscle.

Finally, the change in cell plasticity of HDAC inhibitortreated FAPs isolated from $\mathrm{mdx}$ mice underscores the importance of the cellular environment in shaping the epigenome of the young progenitor cells. While this study reveals an inducible myogenic potential of FAPs, their direct contribution to muscle regeneration remains unknown, and lineage tracing studies will be needed to determine the incorporation of FAPs into the in vivo regenerating myofibers in HDAC inhibitor-treated $\mathrm{mdx}$ mice. Nevertheless, the observation of a global change in chromatin structure in FAPs treated with HDAC inhibitors demonstrates the therapeutic potential of epigenome-modifying drugs. Given that the HDAC inhibitor givinostat is currently in clinical trials for the treatment of $\mathrm{DMD}$, identification of the BAF60c-myomiR axis as a key mediator of HDAC inhibitor-induced changes in FAP plasticity provides us with a potential series of biomarkers to evaluate disease progression and response to treatment. Further characterization of the mechanisms directing the changes in chromatin structure that permit the activation of the myomiR/BAF60c network will be important to the development and refinement of future therapies with epigenetic drugs to treat degenerative diseases such as DMD.

\section{Acknowledgments}

We thank Dr. Michael Rudnicki and Dr. Marjorie Brand (Ottawa Hospital Research Institute) for insightful discussions. Work in the Dilworth laboratory is supported by grants from the Canadian Institutes of Health Research. F.J.D. is the Canada Research Chair in Epigenetic Regulation of Gene Expression. H.F. is the recipient of a post-doctoral fellowship from the Association Française contre les Myopathies.

\section{References}

Davis RL, Weintraub H, Lassar AB. 1987. Expression of a single transfected cDNA converts fibroblasts to myoblasts. Cell 51: $987-1000$.
De Luca A. 2012. Pre-clinical drug tests in the mdx mouse as a model of dystrophinopathies: an overview. Acta myologica 31: 40-47.

Forcales SV, Albini S, Giordani L, Malecova B, Cignolo L, Chernov A, Coutinho P, Saccone V, Consalvi S, Williams R, et al. 2011. Signal-dependent incorporation of MyoD-BAF60c into Brg1-based SWI/SNF chromatin-remodelling complex. EMBO J 31: 301-316.

Goljanek-Whysall K, Pais H, Rathjen T, Sweetman D, Dalmay T, Munsterberg A. 2012. Regulation of multiple target genes by miR-1 and miR-206 is pivotal for C2C12 myoblast differentiation. J Cell Sci 125: 3590-3600.

He WA, Berardi E, Cardillo VM, Acharyya S, Aulino P, ThomasAhner J, Wang J, Bloomston M, Muscarella P, Nau P, et al. 2013. NF-кB-mediated Pax7 dysregulation in the muscle microenvironment promotes cancer cachexia. I Clin Invest 123: $4821-4835$.

Heredia JE, Mukundan L, Chen FM, Mueller AA, Deo RC, Locksley RM, Rando TA, Chawla A. 2013. Type 2 innate signals stimulate fibro/adipogenic progenitors to facilitate muscle regeneration. Cell 153: 376-388.

Joe AW, Yi L, Natarajan A, Le Grand F, So L, Wang J, Rudnicki MA, Rossi FM. 2010. Muscle injury activates resident fibro/ adipogenic progenitors that facilitate myogenesis. Nat Cell Biol 12: 153-163.

Judson RN, Zhang RH, Rossi FM. 2013. Tissue-resident mesenchymal stem/progenitor cells in skeletal muscle: collaborators or saboteurs? FEBS J 280: 4100-4108.

Liu L, Cheung TH, Charville GW, Hurgo BM, Leavitt T, Shih J, Brunet A, Rando TA. 2013. Chromatin modifications as determinants of muscle stem cell quiescence and chronological aging. Cell reports 4: 189-204.

Mozzetta C, Consalvi S, Saccone V, Tierney M, Diamantini A, Mitchell KJ, Marazzi G, Borsellino G, Battistini L, Sassoon D et al. 2013. Fibroadipogenic progenitors mediate the ability of HDAC inhibitors to promote regeneration in dystrophic muscles of young, but not old Mdx mice. EMBO molecular medicine 5: 626-639.

Obokata H, Wakayama T, Sasai Y, Kojima K, Vacanti MP, Niwa H, Yamato M, Vacanti CA. 2014. Stimulus-triggered fate conversion of somatic cells into pluripotency. Nature 505: 641-647.

Saccone V, Consalvi S, Giordani L, Mozzetta C, Barozzi I, Sandoná M, Ryan T, Rojas-Muñoz A, Madaro L, Fasanaro P, et al. 2014. HDAC-regulated myomiRs control BAF60 variant exchange and direct the functional phenotype of fibro-adipogenic progenitors in dystophic muscles. Genes Dev (this issue). doi: 10.1101/gad.234468.113.

Uezumi A, Fukada S, Yamamoto N, Takeda S, Tsuchida K. 2010. Mesenchymal progenitors distinct from satellite cells contribute to ectopic fat cell formation in skeletal muscle. Nat Cell Biol 12: 143-152. 


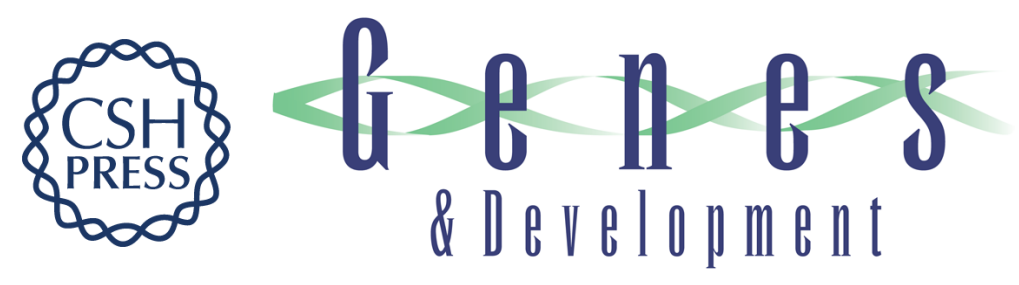

\section{Dystrophic muscle environment induces changes in cell plasticity}

Herve Faralli and F. Jeffrey Dilworth

Genes Dev. 2014, 28:

Access the most recent version at doi:10.1101/gad.241182.114

Related Content HDAC-regulated myomiRs control BAF60 variant exchange and direct the functional phenotype of fibro-adipogenic progenitors in dystrophic muscles

Valentina Saccone, Silvia Consalvi, Lorenzo Giordani, et al.

Genes Dev. April , 2014 28: 841-857

References This article cites 12 articles, 1 of which can be accessed free at:

http://genesdev.cshlp.org/content/28/8/809.full.html\#ref-list-1

Articles cited in:

http://genesdev.cshlp.org/content/28/8/809.full.html\#related-urls

Creative This article is distributed exclusively by Cold Spring Harbor Laboratory Press for the first Commons

License

six months after the full-issue publication date (see

http://genesdev.cshlp.org/site/misc/terms.xhtml). After six months, it is available under a Creative Commons License (Attribution-NonCommercial 4.0 International), as described at http://creativecommons.org/licenses/by-nc/4.0/.

Email Alerting Receive free email alerts when new articles cite this article - sign up in the box at the top Service right corner of the article or click here.

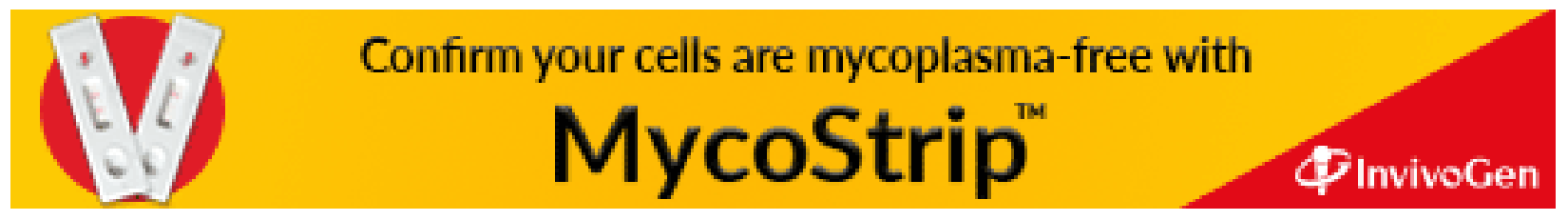

